\title{
Propranolol Application in Gynaecological Disease a Review
}

\section{Anter SS*}

Obstetric Gynecology, Cairo University, Egypt

*Corresponding author: Salwa Samir Anter, Obstetric Gynecology, Cairo University, Egypt

Received: October 09, 2018; Accepted: November 12, 2018; Published: November 19, 2018

\begin{abstract}
Propranolol is inhibitor of $\beta-1$ and $\beta-2$ adrenergic receptors $\beta$-adrenergic receptor blocker with reported antioxidant and anti-inflammatory properties used in treatment of hypertension, angina pectoris, myocardial infarction, migraines, anxiety disorders, and tremor but why limited used in gynecology field in spite of many action either by beta receptor block or no receptor blocker mechanism it act as anti-inflammatory anticancer inhibition Angiogenesis, antioxidant, affected apoptosis, wound healing. We discussed its known used as local contraceptive and treatment of Vulovagnitis by inhibited motility and growth of Giardia lamblia and Trichomonas vagina and treated genital hemangioma and discused also expermential studies on effective on polycystic ovary and in endometrosis.
\end{abstract}

\section{Introduction}

Propranolol is a drug with beta-blocker effect and used clinical in treated hypertension thyrotoxicosis, and recent in capillary hemangiomas, anxiety, and essential tremors [1]. But clinical applications in gynecology is limited and route of administration oral route, injection but what about vagina route is used only as spermicidal effect function. Propranolol is beta blocker that crosses the bloodbrain barrier Propranolol and blood vessele either vasoconstriction via beta-adrenergic antagonists or through inhibition of NO synthesis and NO release [2]. But both action obvious in study of Sonia Maccair. Demonstrated biphasic according to dose With low dose vasoconstricton effect is obvious but with high dose vasodilation effect is dominant as regards vasodilation action alone in study of Priviero FB et al in experimental study on rat the prolonged administration of propranolol after block of nitric oxdie the vasodilation action by three mechanism first mechansim gumentum of the relaxation effect of acetycholine. Second mechanism block calcium entry into vascular smooth muscle thrid mechanism. Increase No bioavailability [3-8]. Propranolol could readily concentrate into the lysosomes and raise the intralysosomal $\mathrm{pH}$ in study of make IT et al. So has has protective effect against iron load-mediated cytotoxicity [9]. The release and uptake of iron by macrophage is Sensitive to Propranolol study by Andrei M et al result [10]. Propranolol antioxdant effect and reduces cardiac Fe uptake as well as antinflammatory so preserve cardiac function during Fe overload [11]. Other study of antioxidat action by Dimitra Taprantzi. Propranolol reduces systemic oxidative stress and endotoxemia in cirrhotic patients with esophageal varices [12]. Propranolol inhbition of matrix metalloproteinase-2 activity by in immunocompetent cells. By study of Ftemeh Hajighasem [13], propranolol induce apoptosis [14]. Propranolol has serotonin antagonist effect $[15,16]$.

\section{Propranolol and Voltage-Gated Sodium Channels}

Propranolol known has membrane stabilizing effect as it block sodium channel so function as local anaesthetic effect, anti arrhythmic and has central nervous system effects $[17,18,19]$.

\section{Application in Gynecology}

Propranolol used in treatment of many diseases but used in gynecology diseases in clinical pactrial not mentioned in spite of many studies mentioned its multiple mechanism of action. Propranolol is the only Food and Drug Administration approved therapy for treatment of patients with hemangiomas vascular anomaly and should be considered first-line therapy for genital infantile hemangiomas.

\section{Propranolol has analgesic and anesthetic effect}

Propranolol relief pain of vagnitis and in vulovagnitis this results obvious more in women with diabetes vulovagnitis as in my previous study on the effect of propranolol on diabetic vulovagnitis the first symptom is decrease soreness and pain. Anter S study agree with others study, as main complained of women with diabetic vulovagnitis is pain and soreness [20].

Due to neuropathy and increase nerve growth factor in diabetic women which decrease by propranolol in study Panel Yu [21], propranolol acts as a local anesthetic my more potent and longer than lidocaine and producing a cutaneous analgesic effect following subcutaneous injection [22]. By decreasing $\mathrm{Na}^{+}$and $\mathrm{Ca}^{2+}$ influxes $[22,23]$, propranolol decrease of neuronal excitability in nociception [24] by two mechansim first as mention above affected $\mathrm{Ca}^{2+}$ and $\mathrm{Na}^{+}$channels activity second mechanism is decrease of intracellular cAMP [25] and so reduction of the adenylcyclase activity [26], third mechanism inhibit the phospholipase A [27], fourth mechanism attenuates interleukin-6 [28], fifth mechanism affected tumor necrosis factor release [29] all the fifty actions are linked to analgesia.

\section{Propranolol and vaginal infection}

Propranolol affected motility of sperm by inhibition and used as spermidical [30] from this mechanism affected other motile organism as trichomonas infection and guardian. Farthing et al., study [31], adds to trichomonas and giardia infection cause vagnitis and can treatment by propranolol also propranolol can combat candida albican by inhibits hyphal development affected the appearance of germ tubes by inhibition without decreasing growth rate by mechansim may be due to binding by propranolol of phosphatidic acid [32]. 


\section{Propranolol and defence against bacterial infection}

This obvious in study of Michael Buckley R that propranolol affected granulocyte adherence and maintain normal function [33]. This function may uself on other situations associated with impaired adherence such as glucocorticoid therapy [34] and multiple myeloma [35].

Effect on vagina of rat as it applied local thickness of the vaginal epithelium was reduced by each treatment and propranolol solution caused significantly more damage than buffer alone in study of on rat Julie L, et al. [36].

As in numerous study, clarify impact of propranolol in poycystic ovary in creature think about as well as in endometrosis. So we should be said first examination on its impact in polycystic ovary in investigation of P. Silva et al clarified enhanced of pathology. With propranolol, blocking ovarian beta-adrenergic receptor was appeared to be a decent instrument to keep the beginning of PCOS actuated by thoughtful hyperactivation [37]. Propranolol and viability on endometrosis propranolol may stifle endometrial tissue by its antiangiogenic movement through inhibitory activities on VEGF, MMP-2, and MMP-9 [38].

\section{Conclusion}

Propranolol is a medication of the beta blocker type treated hypertension and others away from gynecological field and by route other than vagina route inspire of its effectiveness route and less side effect but clinical applications in gynecology is limited to spermicidal and combat infection and genital hemangioman aim of review to open eyes on possible used of Propranolol in polycystic ovary and endometrosis and pass from animals study for more studies.

\section{References}

1. Bryson, Peter D. Comprehensive review in toxicology for emergency clinicians ( $3^{\text {rd }}$ edition). Washington, DC: Taylor \& Francis. 1997; 167

2. Sonia Maccari, Maria Buoncervello, Rampin A, Spada M, Macchia D, Giuseppe Marano, et al. Biphasic effects of propranolol on tumour growth in B16F10 melanoma $\square$ bearing mice. Br J Pharmacol. 2017; 174: 139-149.

3. Priviero FB, Teixeira CE, Claudino MA, De Nucci G, Zanesco A, Antunes E. Vascular effects of long-term propranolol administration after chronic nitric oxide blockade. Eur J Pharmacol. 2007; 571: 189-196.

4. Giavazzi R, Sennino B, Coltrini D, Garofalo A, Dossi R, Ronca R, et al. Distinct role of fibroblast growth factor-2 and vascular endothelial growth factor on tumor growth and angiogenesis. Am J Pathol. 2003; 162: 1913-1926.

5. StilesJ, AmayaC, PhamR, Rowntree RK, Lacaze M, Mulne A, et al Propranolol treatment of infantile hemangioma endothelial cells: a molecular analysis. Exp Ther Med. 2012; 4: 594-604.

6. Lamy S, Lachambre MP, Lord-Dufour S, et al. Propranolol suppresses angiogenesis in vitro: inhibition of proliferation, migration, and differentiation of endothelial cells. Vascul Pharmacol. 2010; 53: 200-208.

7. Hu HT, MaQY, Zhang D, Shen SG, Han L, Ma YD, et al. HIF-1alpha links beta-adrenoceptor agonists and pancreatic cancer cells under normoxic condition. Acta Pharmacol Sin. 2010; 931: 102

8. Alamo Ines G, Kannan Kolenkode B, Bible Letitia E, Loftus Tyler J, Ramos Harry, Efron Philip A, et al. Daily propranolol administration reduces persistent injury-associated anemia after severe trauma and chronic stress. Journal of Trauma and Acute Care Surgery. 2017; 82: 714-721.

9. Mak IT1, Chmielinska JJ, Nedelec L, Torres A, Weglicki WB. D-propranolol attenuates lysosomal iron accumulation and oxidative injury in endothelial cells. J Pharmacol Exp Ther. 2006; 317: 522-528.
10. Andrei M Komarov, Jonathon M Hall, Joanna J Chmielinska, William B Weglicki. Iron Uptake and Release by Macrophages is Sensitive to Propranolol. Molecular and Cellular Biochemistry. 2006; 288: 213-217.

11. Kramer JH, Spurney CF, lantorno M, Tziros C, Chmielinska JJ, Mak IT, Weglicki WB. d-Propranolol protects against oxidative stress and progressive cardiac dysfunction in iron overloaded rats. Can J Physiol Pharmacol. 2012; 90: 1257-1268.

12. Dimitra Taprantzi, Dimitrios Zisimopoulos, Konstantinos C Thomopoulos, Iris Spiliopoulou, Christos DG, Stelios FA. Propranolol reduces systemic oxidative stress and endotoxemia cirrhotic patients with esophageal varices. The Hellenic Society of Gastroenterology Annals of Gastroenterology. 2018; 31: 224-230.

13. Ftemeh Hajighasema. Inhibition of matrix metalloproteinase-2 activity by propranolol in immunocompetent cells. European Respiratory Journal. 2013; 42: 3151.

14. Yuanzheng Chen, Nan Bai, Jianhai Bi, Juan Zhang, Xequing $\mathrm{Li}$, et al Propranolol induces apoptosis in endothelial cells by inhibiting Akt and ERK phosphorylation and MAPK signaling pathway. J Clin Exp Med. 2017; 10: 13167-1317.

15. Davids E, Lesch KP. "[The 5-HT1A receptor: a new effective principle in psychopharmacologic therapy?]". Fortschr Neurol Psychiatr. 1996; 64: 460472.

16. Hoyer D, Clarke DE, Fozard JR, Hartig PR, Martin GR, Mylecharane EJ, et al. "International Union of Pharmacology classification of receptors for 5-hydroxytryptamine (Serotonin)". Pharmacol Rev. 1994; 46: 157-203.

17. Wang DW, Mistry AM, Kahlig KM, Kearney JA, Xiang J, George AL Jr. "Propranolol blocks cardiac and neuronal voltage-gated sodium channels". Front. Pharmacol. 2010; 1: 144.

18. Bankston JR, Kass RS. "Molecular determinants of local anesthetic action of beta-blocking drugs: implications for therapeutic management of long QT syndrome variant 3". J Mol Cell Cardiol. 2010; 48: 246-253.

19. Desaphy JF, Pierno S, De Luca A, Didonna P, Camerino DC. "Different ability of clenbuterol and salbutamol to block sodium channels predicts their therapeutic use in muscle excitability disorders". Mol Pharmacol. 2003; 63: 659-670.

20. Salwa samir anter. Local Application of Propranolol and Treatment of Diabetic Vulovagnitis. Gynecol Obstet. 2018; 8: 475.

21. Chen YW, Chu CC, Chen YC, Hung CH, Wang JJ. Propranolol elicits cutaneous analgesia against skin nociceptive stimuli in rats. Neurosci Lett. 2012; 524: 129-132.

22. Matthews JC, JK Baker. Effects of propranolol and a number of its analogues on sodium channels. Biochemical Pharmacology. 1982; 31: 1681-1685.

23. Akaike N, Ito H, Nishi K, Oyama Y. Further analysis of inhibitory effects of propranolol and local anaesthetics on the calcium current in Helix neurones. Br J Pharmacol. 1982; 76: 37-43.

24. Matthews JC, Baker JK. Effects of propranolol and a number of its analogues on sodium channels. Biochemical Pharmacology. 1982; 31: 1681-1685.

25. Brown AM, Birnbaumer L. Direct G protein gating of ion channels. American Journal of Physiology. 1988; 254: H401-H410.

26. Taussig R, Gilman AG. Mammalian membrane-bound adenylyl cyclases. Journal of Biological Chemistry. 1995; 270: 1-4.

27. Trotz M, Jellison EJ, Hostetler KY. Propranolol inhibition of the neutral phospholipases A of rat heart mitochondria, sarcoplasmic reticulum and cytosol. Biochemical Pharmacology. 1987; 36: 4251-4256.

28. Soszynski D, Kozak W, Conn CA, Rudolph K, Kluger MJ. Beta-adrenoceptor antagonists suppress elevation in body temperature and increase in plasma IL-6 in rats exposed to open field. Neuroendocrinology. 1996; 63: 459-467.

29. Bloksma N, Hofhuis F, Benaissa-Trouw B, Willers J. Endotoxininducedrelease of tumour necrosis factor and interferon in vivo is inhibited by prior adreno- ceptor blockade. Cancer Immunology, Immunotherapy: CII 14. $1982 ; 14: 41-45$. 
30. J Zipper, Wheeler RG, Potts DM, Rivera M. Propranolol as a novel, effective spermicide: preliminary findings. European Journal of Obstetrics \& Gynecology and Reproductive Biology. 2014; 182: 167-171

31. Farthing MJG, Inge PMG, Pearson RM. Effect of D-propanolol on growth and motility of flagellate protozoa1. Journal of Antimicrobial Chemotherapy. 1987; 20: $519-522$.

32. Carol A Baker, Kevin Desrosiers, Joseph W. Propranolol Inhibits Hyphal Development in Candida albicans. Dolan Anti microb Agents Chemother. 2002; 46: 3617-3620.

33. Buckley RM, Ventura ES, Rob Roy MacGregor. Propranolol Antagonizes the Anti-Inflammatory Effect of Alcohol and Improves Survival of Infected Intoxicated Rabbits. J Clin Invest. 1978; 62: 554-559.

34. MacGregor RR, Spagnuolo PS, Lentnek AL. Inhibition of granulocyte adherence by ethanol, prednisone, and aspirin, measured with a new assay system. N Engl J Med. 1974; 291: 642-646.
35. MacGregor RR. The effect of anti-inflammatory agents and inflammation on granulocyte adherence. Evidence for regulation by plasma factors. Am J Med. 1976; 61: 597-607.

36. Julie L Richardson O, Pawanjit S Minhas, Norman W Thomas, Lisbeth Illum. Vaginal administration of propranolol to rats: Absorption and histological effects on the vaginal epithelium. International Journal of Pharmaceutics. 1989; 56: R1-R4.

37. Silva Barros P, Kalil B, Anselmo-Franci J. Propranolol prevents stress induced polycystic ovary syndrome Endocrine Abstracts. 2012; 29: 924.

38. Uzunlar O, Ozyer S, Engin-Ustun Y, Moraloglu O, Gulerman HC, Caydere $M$. Effects of repeated propranolol administration in a rat model of surgically induced endometriosis European. Journal of Obstetrics \& Gynecology and Reproductive Biology. 2014; 182: 167-171.
Austin J Obstet Gynecol - Volume 5 Issue 8 - 2018

Submit your Manuscript | www.austinpublishinggroup.com

Anter. ( ) All rights are reserved
Citation: Anter SS. Propranolol Application in Gynaecological Disease a Review. Austin J Obstet Gynecol. 2018; 5(8): 1127 